\title{
Wet Chemical Oxidation of Organic Waste Using Nitric-Phosphoric Acid Technology
}

by

R. A. Pierce

Westinghouse Savannah River Company

Savannah River Site

Aiken, South Carolina 29808

R. R. Livingston

D. A. Burge

DOE Contract No. DE-AC09-96SR18500

This paper was prepared in connection with work done under the above contract number with the U. S. Department of Energy. By acceptance of this paper, the publisher and/or recipient acknowledges the U.S. Government's right to retain a nonexclusive, royalty-free license in and to any copyright covering this paper, along with the right to reproduce and to authorize others to reproduce all or part of the copyrighted paper. 


\section{DISCLAIMER}

Portions of this document may be illegible in electronic image products. Images are produced from the best available original document. 


\section{DISCLAIMER}

This report was prepared as an account of work sponsored by an agency of the United States Government. Neither the United States Government nor any agency thereof, nor any of their employees, makes any warranty, express or implied, or assumes any legal liability or responsibility for the accuracy, completeness, or usefulness of any information, apparatus, product, or process disclosed, or represents that its use would not infringe privately owned rights. Reference herein to any specific commercial product, process, or service by trade name, trademark, manufacturer, or otherwise does not necessarily constitute or imply its endorsement, recommendation, or favoring by the United States Government or any agency thereof. The views and opinions of authors expressed herein do not necessarily state or reflect those of the United States Government or any agency thereof.

This report has been reproduced directly from the best available copy.

Available to DOE and DOE contractors from the Office of Scientific and Technical Information, P. O. Box 62, Oak Ridge, TN 37831; prices available from (423) 576 $\$ 8401$.

Available to the public from the National Technical Information Service, U. S. Department of Commerce, 5285 Port Royal Road, Springfield, VA 22161. 


\section{WET CHEMICAL OXIDATION OF ORGANIC WASTE USING NITRIC-PHOSPHORIC ACID TECHNOLOGY \\ FY97 SUMMARY REPORT}

R. A. Pierce, D. A. Burge, and R. R. Livingston

Westinghouse Savannah River Company

Savannah River Site

Aiken, SC 29802 


\section{SUMMARY}

Experimental progress has been made in a wide range of areas which support the continued development of the nitric-phosphoric acid oxidation process for combustible, solid organic wastes. An improved understanding of the overall process operation has been obtained, acid recovery and recycle systems have been studied, safety issues have been addressed, two potential final waste forms have been tested, preliminary mass flow diagrams have been prepared, and process flowsheets have been developed. The flowsheet developed is essentially a closed-loop system which addresses all of the internally generated waste streams. The combined activities aim to provide the basis for building and testing a 250-400 liter pilot-scale unit.

Variations of the process now must be evaluated in order to address the needs of the primary customer, SRS Solid Waste Management. The customer is interested in treating job control waste contaminated with Pu-238 for shipment to WIPP. As a result, variations for feed preparation, acid recycle, and final form manufacturing must be considered to provide for simpler processing to accommodate operations in high radiation and contamination environments.

\section{INTRODUCTION}

The purpose of this program is to demonstrate a nitric-phosphoric acid destruction technology which can treat a heterogeneous waste by oxidizing the solid and liquid organic compounds while decontaminating noncombustible items. The process will operate below $200^{\circ} \mathrm{C}$ and at atmospheric pressure for most materials and moderate pressures $(<20 \mathrm{psig})$ for complex organics, and will convert hazardous organics and organic substrates to gases and inorganic salts. This development will produce a complete, closed-loop, engineering-scale process which produces little or no organic residue, no liquid effluent, and isolates hazardous and radioactive metals from solution as an iron phosphate glass or phosphate-bonded ceramic.

This technology has been developed specifically to address the needs of the Savannah River Site, other DOE facilities, and commercial nuclear operations; hazardous waste generators in private industry and small-volume generators such as university and medical laboratories may also have need for the technology. Of particular interest to the DOE Complex is the treatment $\mathrm{Pu}-238$ contaminated solid job-control waste (a heterogeneous mixture of plastics, cellulose, lead, rubber, resins, solvents, oils, steel, ceramics, HEPA filters, etc.) at Savannah River. The site currently has $5000 \mathrm{~m}^{3}$ of this waste and projects generating an additional $25000 \mathrm{~m}^{3}$ over the next 30 years. SRS wants to disposition the waste to WIPP, but radiolysis of the organic fraction of the waste by the $\mathrm{Pu}-238$ to form hydrogen gas would require an approximate $100 \mathrm{X}$ dilution of the waste in its current form for shipment.

The technology proposed is unique to the Savannah River Site (SRS). The process is a wet-chemical process for completely oxidizing solid organic waste materials and 
immobilizing the resulting solution. The basis for the process stems from extensive studies conducted at WSRC. The process contains three distinct parts: organic oxidation, acid recycle, and metal stabilization. The oxidation step uses $\mathrm{HNO}_{3}$ in a concentrated phosphoric acid media as the main oxidant for the organic compounds. The nitric acid products from the oxidation, $\mathrm{NO}_{2}$ and $\mathrm{NO}$, can be regenerated in an acid recovery system using air and hydrogen peroxide. Other oxidation byproducts, such as $\mathrm{HCl}$ (a byproduct of PVC oxidation) must removed from the offgas stream. The oxidation of the waste to gaseous products leaves all hazardous ions in solution. Once oxidation is complete, the phosphoric acid stream becomes the primary feedstream for immobilizing the hazardous ions in either an iron phosphate glass $\left(1050-1150^{\circ} \mathrm{C}\right)$ or a magnesium phosphate ceramic (room temperature). Materials that have been oxidized include neoprene, cellulose, nitromethane, polyethylene, PVC, divinylbenzene resins, and oils.

The advantages of this process are that it is low tech, uses inexpensive reagents, operates at relatively low temperature and pressure, can destroy many types of organic materials, and produces solutions which can be readily converted to a stable final form. The process oxidant can be regenerated and should be resistant to a radioactive environment. Also, the final waste forms have been shown to be easy to make and stable for storage. Scaleup should be relatively straight-forward due to the simplicity of the process.

\section{EXPERIMENTAL DISCUSSION AND RESULTS}

\section{Development Areas}

Many different areas were studied and evaluated in conjunction with this program and a complimentary program with the 94-1 Initiatives program. All of the efforts focused on developing a system which could be scaled up to a pilot-scale process. The areas studied include A) construction of an engineering-scale unit, B) oxidation at the bench and engineering scale, C) $\mathrm{HCl}$ removal, D) NOx recovery and recycle, E) materials of construction, F) offgas analysis, G) process monitoring, $\dot{H}$ ) metal retention/behavior of plutonium and uranium, I) final waste forms, J) waste feed mechanisms and material transport, and $\mathrm{K}$ ) operability and reliability. These will be reviewed in order.

\section{A. Construction of an Engineering-Scale Unit}

Discussion: Many things have been demonstrated at the bench scale, but often many operability issues surface when scaling a system up to the production scale. Therefore, it is essential to conduct pilot-scale testing of the oxidation and nitric acid recycle systems. Focus was placed on demonstrating the optimal system operating parameters. This involves determining the conditions which provide the highest oxidation rates while minimizing nitric acid consumption and volatility. The target for volatility is to keep nitric acid volatility to less than $15 \%$. Metal partitioning will also be studied to determine if any decomposed metals are being entrained into the acid recycle system. Attention will be placed on the performance of the acid recycle system. Specific testing will be 
performed to measure chloride partitioning, acid absorption efficiency, hydrogen peroxide use efficiency; and OGE emissions. Further evaluations will be made regarding material transport issues. The main issues are concerned with addition of solids to the oxidation vessel and transfer of the spent phosphoric acid from the same vessel. Additional consideration will be given to the movement of other liquids and gases within the system. Lastly, the demonstration will allow us to evaluate the hardware and software selections made in constructing this 40 -liter system so as to provide feedback for the next scale up.

Results: Information is provided here to give some background into the design. More detailed equipment design discussions have been provided as part of the Mixed Waste Focus Area Test Plan.

The 40-liter pilot-scale vessel was made from glass with a diameter of 12 " and a height of 24". The dimensions were chosen based on the fact that 12 " is a standard diameter for a glass vessel. Glass was chosen due to uncertainties associated with other materials of construction. Although glass has a relatively high corrosion rate (>40 mils/yr @ 160$170^{\circ} \mathrm{C}$ ), it was judged to be resistant enough while providing a material which allows a viewing of the experiments. Due to the fact that glass was used, operating pressures were limited to $15 \mathrm{psig}$. Standard nomographs for glass vessels suggested that an acceptable operating pressure was on the order of $60 \mathrm{psig}$. The oxidation vessel was also fitted with a glass stirrer and a heating mantle; the heating mantle was controlled using a PID temperature controller. A mist eliminator was also manufactured for the offgas stream to limit metals and nitric acid carryover.

Energy balance calculations were performed for the oxidation and acid recycle processes to determine if chillers would be needed for the pilot-scale system. A follow-up experiment was conducted with acid recycle to observe the temperature levels which might be obtained in the acid recovery system if no cooling were provided. The test showed an acid recycle temperature of $85^{\circ} \mathrm{C}$ which is high enough to significantly affect the ability of the system to function as designed. Calculations indicated that a maximum of $6.6 \mathrm{~kW}$ of cooling capacity would be needed for the oxidation vessel, $1.9 \mathrm{~kW}$ for the condenser, and $3.1 \mathrm{~kW}$ for the acid recycle system. A tantalum cooling coil supplied with process water was built for the oxidation vessel.

Other key support equipment for the pilot-scale also had to first be specified and ordered. Among the items ordered were the acid recycle vessels, acid recycle frame, oxidation vessel heater, cooling coils, instrumentation, data acquisition hardware, and data acquisition software. Acid recycle vessels were fabricated in the SRTC Glass Shop to allow visualization of the experiments. The acid recycle frame was made in the SRTC Machine Shop in a manner making it easy to transport. The oxidation vessel was ordered as a two-circuit heating mantle with $2.4 \mathrm{~kW}$ of heating capacity. Cooling coils for the acid recycle system were designed and fabricated in SRTC; 304-L stainless steel was selected as the material. Instrumentation was kept simple throughout the process. Type $J$ thermocouples were used for all temperature measurements, pressure transducers for 
pressure measurements, and rotameters for gas flow measurements. Temperature and pressure readings were continuously monitored using Opto 22 hardware and Wonderware software.

The use of pumps was not a major concern based on prior experience in the lab-scale systems. Work over several years in the lab showed that phosphoric acid solutions were fluid enough to permit transfer of them using lab-scale pumps. All pumps selected for the pilot were variable-speed peristaltic pumps. All pumps used Viton ${ }^{\mathrm{TM}}$ flexible tubing which has exceptional chemical resistance.

\section{B. Oxidation Testing}

Discussion: A key to determining the viability of the process is to determine the effectiveness of oxidation and oxidation rates for the target waste stream and other applicable streams. Also, it is necessary to begin to assess the cumulative effect of continuous oxidation on the oxidation process. Compounds which were studied include cellulose, neoprene, polyethylene, and PVC. The objective of the experiments was not to obtain the maximum possible rate, but rather what is understood to be the maximum practicable rate based on desired temperatures and pressures.

\section{Results:}

The earliest tests aimed at determining the amount of cellulosic material which can be decomposed into a fixed volume of phosphoric acid. This helps estimate expected volume reductions during overall processing. When complete, 240 grams of KimWipes ${ }^{\mathrm{TM}}$ were oxidized in $70 \mathrm{~mL}$ of phosphoric acid. Some precipitates started to form after 120 grams and the oxidation rate was being impeded by the presence of other ions in solution. Examination of the solids clearly indicates that they are silicates from cellulose; plastics should not have these impurities. The residual phosphoric acid was then immobilized into $43 \mathrm{~mL}$ of iron phosphate glass without difficulty. This is a waste loading density of $349 \# / c u . f t$. Based on estimates from SRS Solid Waste Management, 55 gallon waste drums have approximately $25 \#$ of organic waste, or 3.4\#/cu.ft. Even if it is assumed that all organic in a drum is cellulose, volume reduction should be on the order of 50-100X depending on where the processing endpoint is established.

A series of small-scale experiments were conducted in a radioactive hood in an effort to detect plutonium carryover (work discussed in detail in Section $\mathrm{H}$ ): One longer test processed 25 grams of cellulose through $600 \mathrm{~mL}$ of solution in a $1200 \mathrm{~mL}$ vessel over the course of one hour without plutonium carryover occurring. Because cellulose is $44.4 \%$ carbon, this translates into a throughput of $220 \mathrm{~kg} \mathrm{C}$ per cubic meter of vessel per 24 hours. Without optimization, this is slightly above the $200 \mathrm{~kg} \mathrm{C}$ limit in the TDRD. 
Another test was run to show the oxidation profile which represents the release of carbon dioxide gas from the destruction of a waste mixture containing paper, polyethylene, neoprene, and PVC. Three batch additions were made an hour apart and oxidation was observed at $200^{\circ} \mathrm{C}$ and $12-15$ psig. As expected, paper decomposed within three minutes, polyethylene within 15 minutes, neoprene within 30 minutes, and PVC at about an

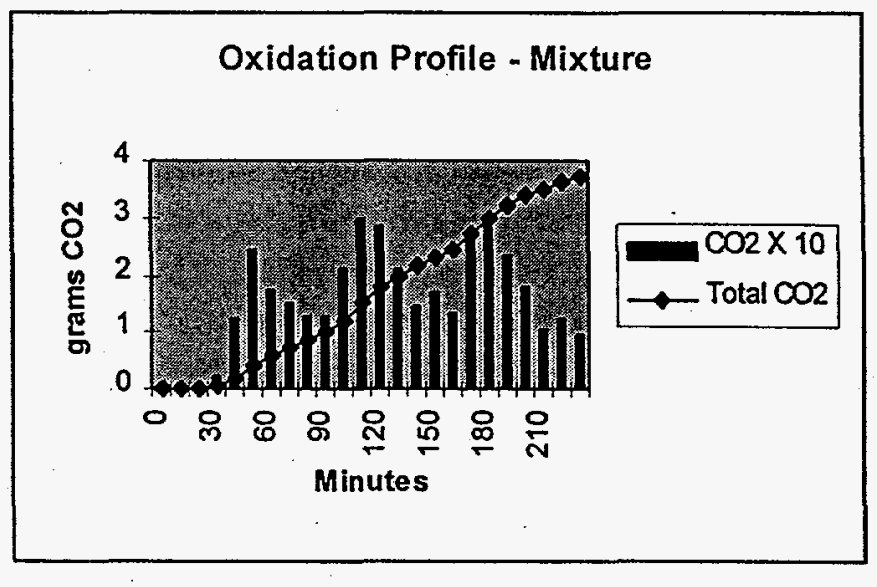
hour. Although neoprene has a faster oxidation rate than polyethylene, its thickness and resistance to melting cause it to take longer to decompose. The response is shown in the figure. The addition of solids more frequently would have caused the carbon dioxide release peaks to overlap.

A series of engineering-scale experiments were conducted in the 40-liter vessel with approximately 16.5 liters of phosphoric acid. Tests included the oxidation of individual compounds (cellulose, neoprene, and polyethylene [PE]) at a range of parameters such as temperature, pressure, and acid concentration. A table of batch testing results are shown below. These reflect what has been observed during lab-scale tests. It is clear that there are clear temperature, pressure, and acid concentration effects.

\begin{tabular}{cc} 
Expt.\# & Temp (C) \\
\cline { 1 - 2 } 1 & 155 \\
2 & 170 \\
3 & 155 \\
4 & 170 \\
5 & 185 \\
6 & 170 \\
7 & 170 \\
8 & 170 \\
9 & 185 \\
10 & 185 \\
11 & 170
\end{tabular}

$[H+](M)$
0.5
acid def.
1.0
0.5
0.5
0.8
1.0
0.6
0.4
0.4
0.6

\begin{tabular}{|c|c|}
\hline$P$ (psig) & Waste \\
\hline 4 & $41 \mathrm{~g}$ cellulose \\
\hline 4 & 41g cellulose \\
\hline 4 & $30 \mathrm{~g}$ cellulose \\
\hline 5 & $10 \mathrm{~g} P E$ \\
\hline 5 & $10 \mathrm{~g} P E$ \\
\hline 5 & $10 \mathrm{~g} P \mathrm{E}$ \\
\hline 5 & $10 \mathrm{~g}$ neoprene \\
\hline 5 & $10 \mathrm{~g}$ neoprene \\
\hline 5 & $10 \mathrm{~g}$ neoprene \\
\hline 8 & $15 \mathrm{~g} P \mathrm{E}$ \\
\hline 8 & $15 \mathrm{~g} P E$ \\
\hline
\end{tabular}

Decomposition
$\begin{gathered}\text { Times } \\ 2 \mathrm{~min} \\ >30 \mathrm{~min} \\ 2 \mathrm{~min} \\ 80 \mathrm{~min} \\ 35 \mathrm{~min} \\ 35 \mathrm{~min} \\ 30 \mathrm{~min} \\ 40 \mathrm{~min} \\ 45 \mathrm{~min} \\ 25 \mathrm{~min} \\ 20 \mathrm{~min}\end{gathered}$

Batch tests were also conducted with a mixture of cellulose, neoprene, polyethylene, and $\mathrm{PVC}$ at $170-185^{\circ} \mathrm{C}, 0.5-1.0 \mathrm{M} \cdot \mathrm{HNO}_{3}$, and $8-10$ psig. Consistent with the results above, oxidation of cellulose, neoprene, and polyethylene at $170^{\circ} \mathrm{C}$ and $1.0 \mathrm{M} \mathrm{HNO}_{3}$ occurred at similar rates as at $185^{\circ} \mathrm{C}$ and $0.5 \mathrm{M} \mathrm{HNO}_{3}$; in both cases the neoprene and polyethylene were decomposed inside of 15 minutes. It is expected that the accelerated rate is caused by the oxidation of cellulose which increases the NOx concentration in the solution 
Difficulties were encountered with feeding solids in a continuous manner. The issues surrounding material transport are discussed in Section J. The net result is that the engineering-scale unit could not be tested in continuous mode. Consequently, follow-up work was performed at bench-scale to evaluate whether the throughput capabilities for different organics could meet the proposed requirements.

Tests were run is a vessel containing $200 \mathrm{~mL}$ of phosphoric acid in a semi-continuous mode. Samples were added every 15 minutes over a two-hour period. Polyethylene bag was run in which 1.0 gram samples are added each 15 minutes at $185^{\circ} \mathrm{C}$ and $10-12$ psig. The samples decompose readily throughout the experiment and are oxidized. The rate of addition corresponds to a throughput rate of $206 \mathrm{~kg} \mathrm{C}$ per 24 hours per cubic meter vessel (assuming 50\% freeboard). When the experiment is repeated using a thicker, higher density polyethylene (from bottles). Overall decomposition to completion is slower because of the increase in thickness and density; material take 50 minutes to decompose instead of 10-15 minutes. However, the continuous decomposition rate eventually stabilizes and appears to be consistent with that of the polyethylene bag. Testing with neoprene had not yet been initiated at the end of the fiscal year.

Because of the apparent resistance of PVC to dissolution at $185^{\circ} \mathrm{C}$ and $10 \mathrm{psig}$, oxidation testing was conducted using mixtures of organics in the feed. Tests were run with mixtures of cellulose, neoprene, polyethylene, and PVC. The oxidation characteristics of these tests appear to be consistent with lab-scale experience which show PVC to be the most resistant to oxidation. Based on observations, it is believed that PVC decomposition rate, even when PVC is added in small quantities, will be the rate limiting step in the process. As a result, tests were run at temperatures just above the melting point of PVC (202 deg. C). These showed oxidation of PVC at a rate of approximately $155-180 \mathrm{~kg} \mathrm{C} / \mathrm{m}^{3}$-day (assume $50 \%$ freeboard). However, the raising of the reaction temperature would mean lower concentrations of nitric acid remain soluble, or that system pressure would need to be increased. A separate experiment showed that at $205^{\circ} \mathrm{C}$ and $15 \mathrm{psig}, 0.24 \mathrm{M}$ of nitric acid is soluble. At $220^{\circ} \mathrm{C}$ this falls to $0.02 \mathrm{M}$ while at $190^{\circ} \mathrm{C}$ it is $0.60 \mathrm{M}$.

Another operation concern is endpoint determination. In some cases, as with Pu-238 waste, the endpoint will be dose limited. However, many other situations will be limited by metal solubility. Based on the expected waste composition, the metals of greatest concern are iron, aluminum, silicon, and lead. Each of these metals will have a solubility limit, and how the solution behaves at that limit can be critical.

The greatest concern is with iron precipitation for two reasons. First, it is the most prominent metal in the waste streams. Second, iron phosphate hydrate precipitates as a continuous gelatinous mass. The precipitate does not dissolve in water; in fact, precipitation is even worse if water is added due to the increase amount of water available to form a network of hydrates. As a result, precipitation of iron phosphate must be avoided. This is the basis for promoting at-line analysis of iron concentration in the oxidation vessel. -Preliminary experimental work dissolving $\mathrm{Fe} 2 \mathrm{O} 3$ into $85 \%$ phosphoric 
acid shows the following iron (not iron oxide) solubility: $187 \mathrm{~g} / \mathrm{L}$ at $141^{\circ} \mathrm{C}, 165 \mathrm{~g} / \mathrm{L}$ and $165^{\circ} \mathrm{C}$, and $144 \mathrm{~g} / \mathrm{L}$ at $183^{\circ} \mathrm{C}$. The addition of nitric acid when precipitation starts to occur is effective in solubilizing the precipitate.

Work with silicon coming from paper oxidation and etching of glass vessels shows that the precipitation of silicon phosphate is not problematic. The precipitate it forms is a well-divided, dispersible precipitate. Preliminary experiments with aluminum provide some cause for concern. Work with additions of aluminum nitrate to phosphoric acid at $190^{\circ} \mathrm{C}$ shows an aluminum solubility limit of $75 \mathrm{~g} /$ liter; furthermore, when the precipitate forms, it forms as a gelatinous mass. On the other hand, experiments indicate that the precipitate is water soluble. No work has yet been performed with lead precipitates, but the potential to have pieces of lead metal in the waste dictates that work be performed.

\section{Chloride Removal}

Discussion: The need to remove chloride from the system exists because of byproducts from the oxidation of PVC and neoprene. When oxidized, the chloride forms $\mathrm{HCl}$ which is sufficiently volatile to escape into the offgas system. If not removed separately, the $\mathrm{HCl}$ will end up in the acid recycle system and, subsequently, build up in the system. There are also concerns that the released chloride may form $\mathrm{NOCl}$ and chlorine gas.

The most expedient method for eliminating $\mathrm{HCl}$ involves using water, more specifically condensed water vapor from the oxidation process, to

Theoretical NO3- and Cl-Solubility

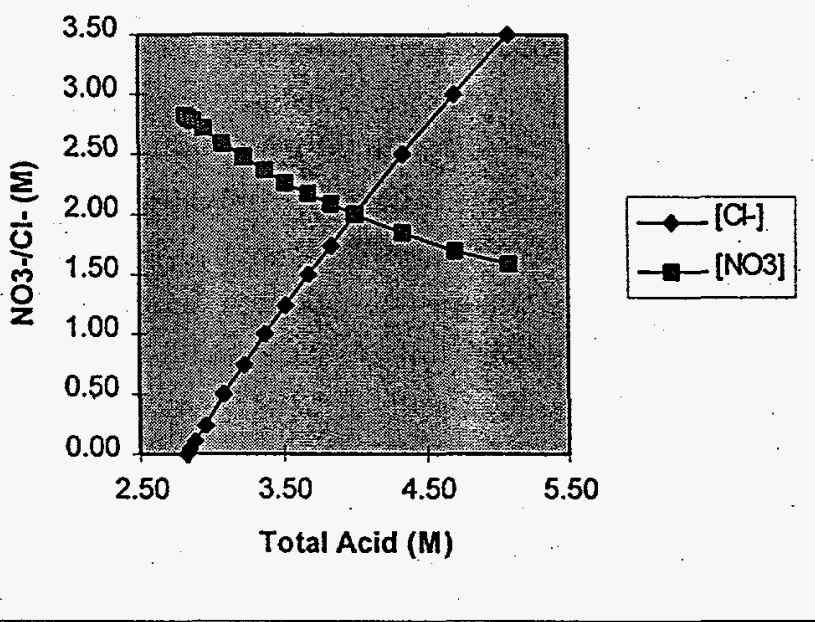
absorb the $\mathrm{HCl}$. Additionally, it is expected that $\mathrm{NOCl}$ would also be absorbed by water via the following reaction:

$$
\mathrm{NOCl}+\mathrm{H}_{2} \mathrm{O} \longrightarrow \mathrm{HNO}_{2}+\mathrm{HCl}
$$

Theoretical evaluations conducted by J. R. Smith suggested that nitric acid concentrations in the water wash would build up to a maximum level long before the $\mathrm{HCl}$ would reach a maximum. Beyond the maximum absorption, NOx would pass through the chloride wash bottle and be absorbed in the first hydrogen peroxide acid recovery vessel. Any chlorine gas that may form would pass completely through the acid recycle system. It is expected. that if the concentration of nitric acid in the chloride wash were to get too high, chloride would be able to pass through the system as either $\mathrm{HCl}$ or $\mathrm{NOCl}$.

Results: 
Pilot testing showed that the chloride wash bottle effectively removed chloride from the offgas from 0-2000 ppm. Data also showed no detectable chloride remaining in the oxidation pot or passing through to the first hydrogen peroxide bottle. However, at the same time it was observed that essentially all of the NOx was also being absorbed in the chloride wash bottle from $0-2.8 \mathrm{M}$ nitric acid (see figure). This was considered potentially problematic. As a result, a small scale experiment observed the chloride and nitric acid scrubbing effects in the chloride wash bottle over a wider range of concentrations. The results, contrary to theory proposed in FY96, indicated that both $\mathrm{NOx}$ and $\mathrm{HCl}$ absorb until they reach a "collective" maximum. What this means is that there would be no point where $\mathrm{HCl}$ would absorb while NOx remained unabsorbed, a condition which is unacceptable for acid recycle.

Follow-up testing at the bench scale evaluated a simple condenser for the removal of $\mathrm{HCl}$ and water vapor without significant absorption of NOx. The first experiment using a simple, small-volume condenser showed retention of approximately $50 \%$ of the $\mathrm{HCl}$ while allowing for NOx passage through the system. The condenser arrangement was then modified to allow for larger condenser volumes to improve

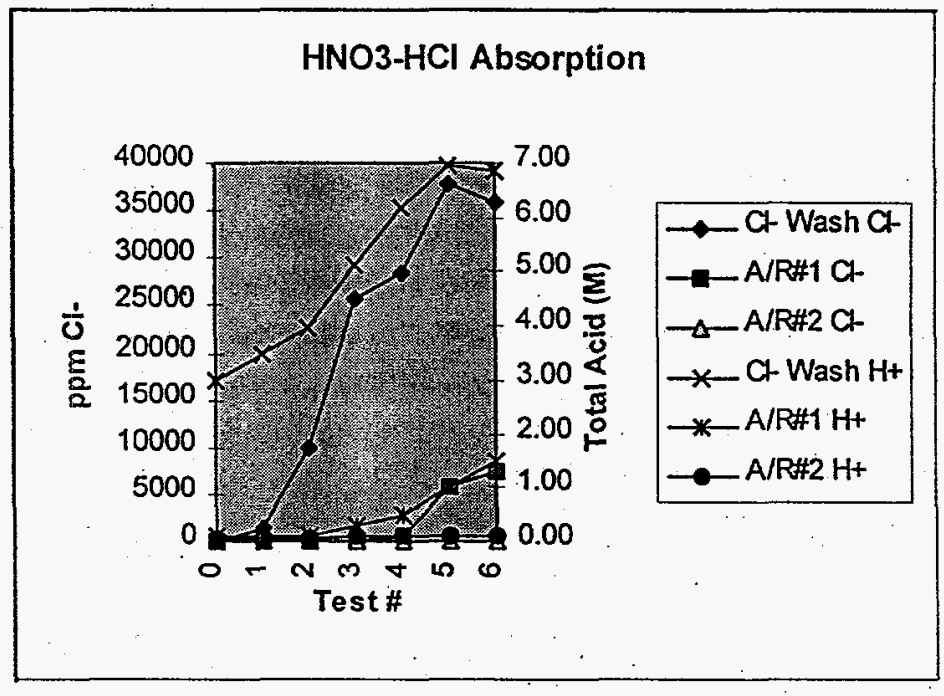
condensation of both $\mathrm{HCl}$ and water. The modified arrangement yielded slightly better results at 57\%. It is unclear at this time whether a condenser needs to be made which has higher contact area for condensing $\mathrm{HCl}$ or whether this stems from the formation of NOCl caused by the reaction of NOx and available chloride. The passage of chloride is more than offset by the improved passage of NOx to the acid recovery system.

\section{NOx Recovery and Recycle}

Discussion: Several approaches exist for the recycle of nitric acid. Some options are proprietary technology of which little is known aside from vendor claims. The most attractive alternative for radioactive service is hydrogen peroxide absorption. Calculations of the maximum theoretical nitric acid concentration expected for absorption of $\mathrm{NO}_{2}$ using hydrogen peroxide indicates that high nitric acid concentrations could be obtained using $30 \%$ hydrogen peroxide. Using the equation

$$
2 \mathrm{NO}_{2}+\mathrm{H}_{2} \mathrm{O}_{2} \longrightarrow 2 \mathrm{HNO}_{3}
$$


FY97 Summary Report SR1-6-MW-32, Task A

it was determined that a maximum concentration of $61.3 \mathrm{wt} \%$ could be obtained with $30 \% \mathrm{H}_{2} \mathrm{O}_{2}$ and 78.7 wt\% with $50 \% \mathrm{H}_{2} \mathrm{O}_{2}$. These calculations do not account for any acid formation which may occur due to $\mathrm{NO}_{2}$ absorption by the balance of water in the hydrogen peroxide solution.

It is important to note that the presence of NO gas in the stream reduces the maximum theoretical concentration. The reaction of NO with $\mathrm{H}_{2} \mathrm{O}_{2}$ is as follows:

$$
2 \mathrm{NO}+3 \mathrm{H}_{2} \mathrm{O}_{2} \longrightarrow 2 \mathrm{HNO}_{3}+2 \mathrm{H}_{2} \mathrm{O}
$$

Not only is peroxide use efficiency reduced, but there is also a dilution effect from the water in the reaction products. This yields theoretical maximum acid concentrations of $47.0 \mathrm{wt} \%$ for $30 \% \mathrm{H}_{2} \mathrm{O}_{2}$ and $60.8 \mathrm{wt} \%$ for $50 \% \mathrm{H}_{2} \mathrm{O}_{2}$.

Results:

Experiments were conducted to study NOx absorption into hydrogen peroxide to confirm design parameters for the pilot-scale acid recycle unit. Four key parameters were evaluated: $\quad \mathrm{NO}: \mathrm{O}_{2}$ ratio, residence time to convert $\mathrm{NO}$ to $\mathrm{NO}_{2}$ prior to absorption, percent hydrogen peroxide, and use of oxygen versus air to convert $\mathrm{NO}$ to $\mathrm{NO}_{2}$. A series of twelve tests were run in which NO was generated, pumped at a constant rate, mixed with an oxygen source fed at a constant rate, through hydrogen

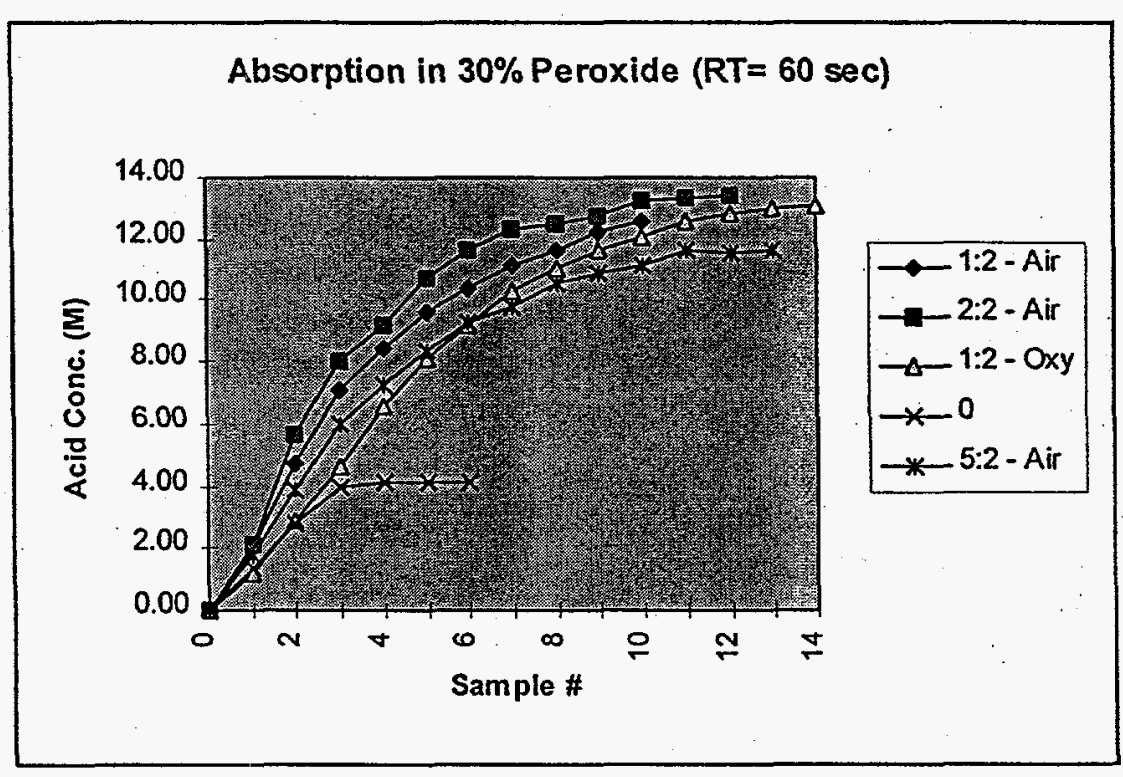
peroxide. The liquid was then titrated to determine acid concentrations. 


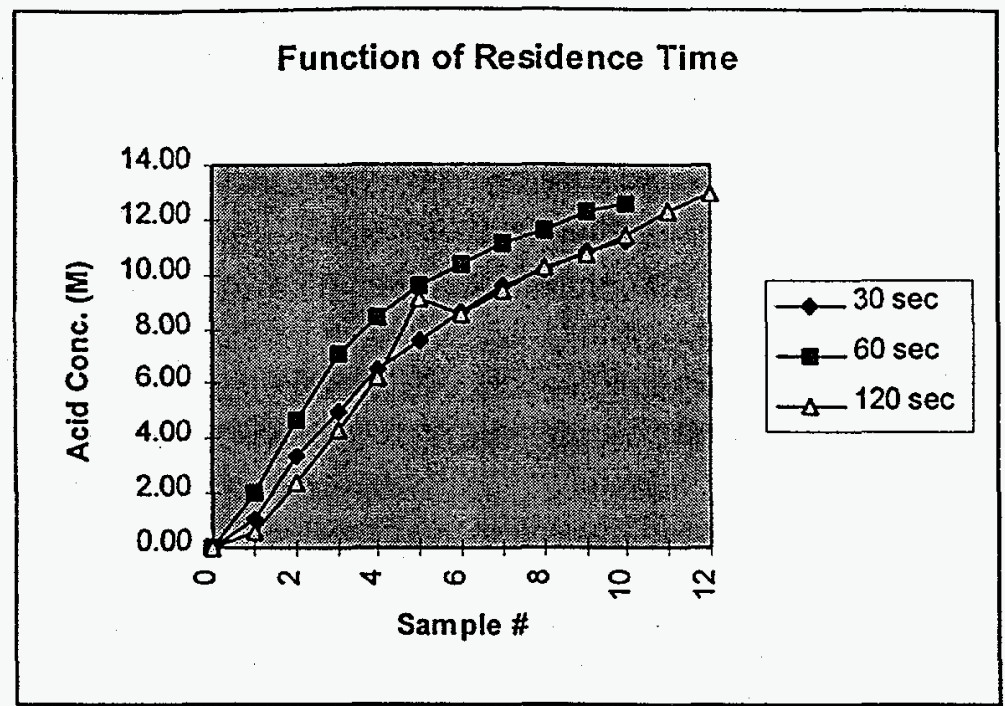

The most important things to note from the data are as follows: 1) tests with pure NO yield a nitric acid concentration of $4.1 \mathrm{M}$ compared to NO and air which yields approximately $13 \mathrm{M}$; 2) controlled absorption conditions have consistently shown conversion of $30 \%$ hydrogen peroxide to above $13 \mathrm{M}$ which is well above the $11.5 \mathrm{M}$ measured under less controlled conditions in FY96; 3) 50\% hydrogen peroxide does not seem to offer an advantage over $30 \%$ peroxide commensurate with the higher cost, concentration, and chemical instability; 4) oxygen does not seem to provide any significant benefit over air; 5) the optimum residence time prior to $\mathrm{NO}_{2}$ absorption is on the order of 60 seconds; the optimum NO:O2 ratio is 2:2 but ratios as low as 1:2 reduce NOx absorption less than $10 \%$.

Experiments were also run using three hydrogen peroxide bottles in series and flowing a small amount of NOx through the system to show how the NOx distributes through the three bottles as a function of acid concentration in the peroxide. The test showed that the hydrogen peroxide in the first bottle will absorb NOx completely until it is about two-thirds consumed before allowing NOx to pass through to the second bottle. Also, throughout the test, continuous monitoring of NOx emissions from the third peroxide bottle always showed $30 \mathrm{ppm}$ or less as compared to the clean air standard limit of 200

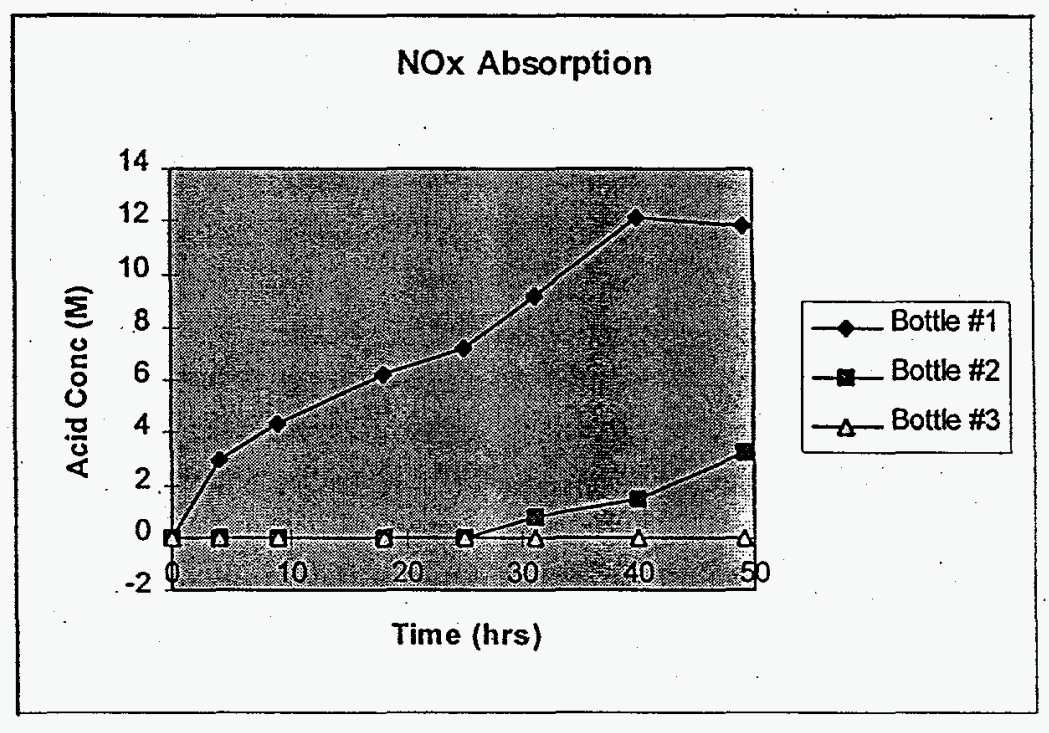
ppm. Absorption efficiency is a function of geometry, but is indicative of what can be expected during the proper use of hydrogen peroxide units in series to absorb NOx to recycle nitric acid.

While the recycle of nitric acid is very attractive in most applications, the specific needs related to SRS Pun238 contaminated job control waste create opportunities for simplified 
offgas treatment options. The restrictions and requirements of handling waste streams with high radiation levels make it attractive to greatly reduce the number of process operations, system complexity, and maintenance issues even at the expense of somewhat higher operation costs. Because of this, several other options are being considered which involve the direct destruction and/or absorption of both $\mathrm{HCl}$ and $\mathrm{NOx}$ instead of the separating the $\mathrm{HCl}$ and recycling the $\mathrm{NOx}$ as nitric acid.

The first approach involves the use of a solution of urea for $\mathrm{HCl}$ absorption and $\mathrm{NO}_{2}$ destruction. Information in the literature shows $\mathrm{NO}_{2}$ destruction by urea via the reaction:

$$
6 \mathrm{NO}_{2}+4 \mathrm{NH}_{2} \mathrm{CONH}_{2} \rightarrow 7 \mathrm{~N}_{2}+8 \mathrm{H}_{2} \mathrm{O}+4 \mathrm{CO}_{2}
$$

As can be seen from the reaction, NO2 goes to nitrogen and the urea forms nitrogen and carbon dioxide. Urea is replenished by simply adding it back into the solution. $\mathrm{HCl}$ would be absorbed in the liquid, and the solution would be replenished with urea until $\mathrm{HCl}$ built up and the solution has to be neutralized, evaporated, and incorporated as part of the final solid waste form. Another similar option uses either water or caustic solution to absorb both $\mathrm{NO}_{2}$ and $\mathrm{HCl}$, which is commercially available technology. Pilot scale experiments show water to be very efficient at absorbing both $\mathrm{NO}_{2}$ and $\mathrm{HCl}$ at low acid concentrations (see chart in Section C). Once again, when necessary, the solution would be neutralized, evaporated, and incorporated into the final waste form. Much of the work on alternative offgas treatments has not yet been conducted and should be part of any development efforts in FY98 so that a comparison can be made between acid recycle and acid destruction.

\section{E. Materials of Construction}

Discussion: Prior-year testing studied the corrosion rates for a wide range of metallic substances along with soda lime glass and Teflon. These tests showed that the only acceptable candidates for use as an oxidation vessel were Teflon and tantalum. Followup tests were performed with several ceramic materials and showed that pyrolytic graphite and $\mathrm{SiC}$ provided excellent resistance while glass-coated vessels were inadequate for the oxidation vessel. This year focused on evaluating Teflon-coated metals for the oxidation vessel, other materials selected for use in the engineering-scale unit, and materials for other support equipment not tested as part of the 40-liter system.

Results: A series of corrosion tests were conducted to identify the preferred material for the oxidation vessel. In one test, two samples were tested in $13.8 \mathrm{M} \mathrm{H} 3 \mathrm{PO} / 1.0 \mathrm{M}$ $\mathrm{HNO} 3 / 0.1 \mathrm{M} \mathrm{HCl}$ at 175 degrees $\mathrm{C}$. One sample was Teflon-coated carbon steel while the other was graphite (which differs from pyrolytic graphite which was successfully tested in FY96). After four days the test had to be stopped because the test solution turned black. A study of the samples showed that high-temperature stabilizers (carbon black) were being leached from the Teflon-coated sample which is unacceptable. The graphite sample, being porous in nature, showed no chemical attack but had become deformed and had absorbed some of the acid. 
A second test reviewed six separate samples -- PVDF, Hastelloy G30, quartz, pyrex, glass-coated steel, and teflon-coated steel. The samples were exposed to $1 \mathrm{M} \mathrm{HNO}$ in concentrated phosphoric acid at $175^{\circ} \mathrm{C}$ for seven days. The observed corrosion rates are as follows (with a corrosion rate below 20 mils/year considered to be "good."): Hastelloy $\mathrm{G} 30=48 \mathrm{mils} / \mathrm{year}$, quartz $=3$ mils/year, pyrex $=48$ mils/year, glass-coated steel $=200$ mils/year, and teflon-coated steel $=5$ mils/year. PVDF was tested and found to warp and offgas within the first few hours. Some concerns exist with respect to the teflon-coated sample because discoloration was observed. The teflon-coated sample was examined using the SEM and standard microscopes. No difference, apart from color, was observed.

Following these tests, the best candidate material appeared to be teflon-coated steel: As a result, a sample was obtained for use in the pilot vessel. The sample was subjected to the wide range of conditions used throughout pilot testing and was found to hold up in a satisfactory manner. Because of this, teflon-coated steel will be the material of choice for future oxidation testing. Other materials which can be used for the oxidation vessel or vessel liner include quartz, tantalum, and pyrolytic graphite.

Pilot testing provided more insight into materials compatibility for the acid recovery system. Somewhat surprising is the apparent compatibility of the cooling coils used in the presence of mixtures of nitric and hydrochloric acids. No signs of attack were observed. Equally surprising is the formation of silica precipitates in the two bottles containing a mixture of nitric acid and hydrogen peroxide. The formation of precipitates indicates the etching of the glass by the mixture. While surprising, this does reflect similar experiences with metal-plated conductivity probes in which the metal was quickly dissolved off of the probe. This is not problematic in that the glass bottles used for the acid recovery system can be replaced with plastic equivalents.

Experimentation was also conducted to identify a suitable crucible for glass formation. The first tests looked at a porous, clay-bonded silica crucible. Static corrosion was smaller than expected, but dynamic corrosion was unacceptably high. Experiments were then conducted with a mullite-zircon (AZS) and a mullite crucible. Both samples showed small amounts of corrosion. Testing of two fused silica materials and one alumina-coated $\mathrm{SiC}$ composite were tested together. The experiment failed in that the glass melt solidified. Examination of the test showed the that the composite was unacceptable due to high $\mathrm{SiC}$ attack which caused melt solidification.

Next, crucible corrosion testing of three fused silica materials from three separate vendors was completed inside an S-clay bonded fused silica crucible. The crucible showed significant corrosion and is unacceptable. The two pure silica samples showed good to excellent corrosion resistance and significant resistance to absorption of liquid into the ceramic (also known as wicking); the two pure silica samples were very sensitive to thermal shock. The third sample, a silica-bonded silica composite showed good corrosion resistance, but showed some signs of wicking. The level of wicking is not 
viewed as problematic. The composite exhibited excellent thermal shock resistance and is the material of choice.

\section{F. Offgas Analysis}

Discussion: An off-gas test series was devised to identify hazardous and volatile components in the off gas that may cause problems in the process. An end-objective was to evaluate dioxin production potential. Three major pathways of dioxin formation are as follows: 1) homogeneous gas phase formation from hydrocarbon products of incomplete combustion at high temperature; 2) catalytic formation of dioxin from organic precursors similar in structure to dioxin at low temperatures (generally $300-500^{\circ} \mathrm{C}$ ); 3) formation in the condensed phase from carbonaceous precursors that are chemically and structurally dissimilar to dioxin ( this "starting from scratch" pathway is sometimes called de novo synthesis).

The first pathway is ruled out because of the low operating temperatures of wet oxidation. The last pathway is not considered likely because of required residence time and the probability of a successful completion of a number of reactions. However, the liquid batch composition in the vessel, with the major composition component being phosphoric acid, was evaluated for suspect analytes, following a series of tests, to determine if a condensed phase mechanism could produce dioxin.

Although the usual temperature range for the second pathway $\left(300-500^{\circ} \mathrm{C}\right)$ is above the highest operating temperature for wet oxidation $\left(200^{\circ} \mathrm{C}\right)$, it has the greatest potential for dioxin formation of the three pathways. Chlorine in the presence of a receptive aromatic compound provides the best mix for dioxin formation for this pathway. The chosen dioxin precursors are pentachlorophenol (PCP) and 2,4,5-trichlorophenol (TCP). (The highly toxic dioxin TCDD is a contaminant of 2,4,5-trichlorophenol manufacture.) Hydrochloric acid and cupric chloride were added to maximize the potential for dioxin formation by the second pathway. A mix of $5 \mathrm{mg}$ of tetrachlorophenol (PCP) and $5 \mathrm{mg}$ of $, 2,4,5$ trichlorophenol was chosen for evaluating off-gas potential for dioxins in the pilot plant 14 liter batch reactor. The amount was determined based on detectable amounts.

Results: On the bench scale, in a system containing $200 \mathrm{~mL}$ of phosphoric acid, a series of tests that covered the range of temperature, pressure, and nitric acid composition were conducted and off-gas and charcoal filter residue samples were collected and evaluated. Next, a series of tests with dioxin precursors was performed. The dioxin-precursor test procedure for the bench scale batch is now described. PCP is added to the phosphoric acid batch to serve as a benzene ring (necessary for a dioxin precursor) with available $\mathrm{Cl}$ at room temperature. About $0.2 \mathrm{~g}$ cupric chloride is added to the concentrated phosphoric acid, also at room temperature. The batch is heated to $130^{\circ} \mathrm{C}$; then nitric acid equivalent to $2 \mathrm{M}$ batch solution is added. The batch is heated to $150^{\circ} \mathrm{C}$; then $0.5 \mathrm{~g}$ cellulose (paper) waste is added. The temperature of the batch is ramped from $150^{\circ} \mathrm{C}$ to $185^{\circ} \mathrm{C}$ over an hour period. After 15 minutes at $185^{\circ} \mathrm{C}$, the process is shutdown. The flask of water 
used for the first scrub and a charcoal filter in-line at the off-gas exit point to the hood are submitted for dioxin analysis.

The water wash was found to contain a total of $0.2 \mathrm{ppm}$ mixed ketones. Ketones are generally thought of as neutral, mobile volatile liquids that are the second step in the oxidation of a hydrocarbon. No chlorinated or aromatic compounds were found. No residue was found in the activated carbon filter downstream of the water and peroxide washes.

The residual concentrated phosphoric acid batch liquid was analyzed following the completed series of eight wet oxidations of paper, neoprene, and other waste types. The residual batch solution contained both chlorinated pyridine and nitrochlorobenzene, but no other related compounds The amount of chlorinated pyridine was determined to be about $5 \mathrm{ppm}$ and nitrochlorobenzene at $0.037 \mathrm{ppm}$.. There were no phenols or dioxins identified in solution.

A wrap-up bench scale test subsequent to the series of pilot and bench tests was conducted with a mixture of TCP and PCP as dioxin precursors. The test evaluated a mixture of $3.5 \mathrm{~g}$ paper, $1 \mathrm{~g}$ polyethylene, $1 \mathrm{~g}$ neoprene, $1 \mathrm{~mL} \mathrm{HCl}$ and $10 \mathrm{mg}$ each of TCP and PCP. Temperature and pressure were at $185^{\circ} \mathrm{C}$ and $8-10 \mathrm{psig}$. A number of analytes was detected in the water sample but not in the charcoal filter. There were no phenols or other dioxins present above to the limit of detection. Alkyl nitrates were present in the water sample at $7.7 \mathrm{mg} / \mathrm{ml}$ of sample water concentration, as well as $440 \mathrm{ug} / \mathrm{ml}$ of short straight chain chlorinated hydrocarbons, such as dichloropentane and dichloropentanol; these are likely products from neoprene destruction. The limit of detection for all analytes, including dioxins, phenols, aromatics, alkyl nitrates, and other alkyl substituted organics in the water sample was $2.0 \mathrm{ug} / \mathrm{ml}$. No analytes were detected in the charcoal tube, at a limit of detection of $10 \mathrm{ug} / \mathrm{tube}$.

Subsequent tests were conducted in the 40 -liter pilot system. Two tests were conducted with batch samples of $22 \mathrm{~g}$ cellulose, $5.2 \mathrm{~g} \mathrm{PE}, 3.5 \mathrm{~g}$ neoprene, and $3.5 \mathrm{~g}$ PVC in $16.5 \mathrm{~L}$ of phosphoric acid. The waste batch was added at $155^{\circ} \mathrm{C}$ for one test and $170^{\circ} \mathrm{C}$ for the second. A third test was conducted with $30 \mathrm{~g}$ cellulose, $15 \mathrm{~g}$ neoprene, $4.5 \mathrm{~g}$ polyethylene, and $5 \mathrm{mg}$ each of TCP and PCP. The phenol mixture was added at $155^{\circ} \mathrm{C}$ and later ramped to $170^{\circ} \mathrm{C}$. First water wash and charcoal filter in the off-gas were analyzed after the second test and after the third test.

The water wash for both tests had an organic mix of 2-4 ppm alkyl nitrates and 0.02-0.10 ppm parachloronitrobenzene: It is postulated that chlorobenzene was released from the batch at about $130^{\circ} \mathrm{C}$ and reacted with nitrous oxides in the gas phase before condensing in the water wash. Also, because the benzene compound was present both from the test with and without phenols but not from small-scale tests not using PVC, it is believed that it is an impurity used in PVC manufacturing. Throughout pilot testing, there were no dioxins or phenols detected. 
A separate emissions concern which must be addressed is $\mathrm{CO}$ release. Throughout the development, it has been known that a small fraction $(<1 \%)$ of carbon is released as CO. This was further supported by data from the oxidation pilot. Detection of $\mathrm{CO}$ from the oxidation pilot, in which there is some dilution from air added to convert $\mathrm{NO}$ to $\mathrm{NO}_{2}$, showed CO release numbers as high as $3000-3500 \mathrm{ppm}$ (or $0.30-0.35 \%$ ). Work needs to be performed to identify what levels would be acceptable and to determine, if necessary, a catalytic method for converting $\mathrm{CO}$ in the offgas stream to $\mathrm{CO}_{2}$.

\section{G. Process Monitoring}

Discussion: For safety, process control, and optimization reasons, it is necessary to be able to monitor and control the process using reliable instrumentation on a nearcontinuous basis. While many of the process readings can be taken using standard thermocouples and pressure transducers, the monitoring of nitric acid in the oxidation vessel is clearly an area in need of technology development. The use of spectrometry is being strongly considered and evaluated against other analytical methods for this application. Material compatibility issues and the need for real-time information preclude the use of some "standard" analytical methods. The desired accuracy for nitric acid monitoring is $+/-0.05 \mathrm{M}$. Other process areas which require evaluation include monitoring of nitric acid and $\mathrm{HCl}$ concentrations in the acid recovery system.

Results: Monitoring nitric acid concentration for the system has required the innovative assembly of components to allow real-time, at-line, analysis of the process. The requirements established for this analysis required analytical results at 10 second intervals over a concentration range of 0.1 to $1.5 \mathrm{M}$ nitric acid in the presence of concentrated phosphoric acid. The accuracy desired was $0.05 \mathrm{M}$ over the analytical range with a precision of $0.02 \mathrm{M}$ inorder to track acid consumption for real-time control.

Early in the process design the use of a minature fiber-optic spectrometer was envisioned in order to combine monitoring capability for iron and plutonium in addition to the nitric acid concentration. This system was anticipated to operate at $300 \mathrm{~nm}$ for the nitrate measurement; however,our early tests demonstrated multiple interferences at this wavelength. The alternative selected after measuring "worst case" samples prepared from small scale oxidation runs containing high loadings of paper, polystryene, and polyethylene was to make the measurments at $210-240 \mathrm{~nm}$ range. The nitrate absorbance at the lower wavelength is about 1000 times more sensitive, allowing application of a shorter flowcell pathlength and minimizing the impact of interfering compounds.

The potential of placing a probe into the reaction vessel was explored for a brief time and abandoned based on current state of technology and our limited development budget. As test of interfering compounds continued, we discovered that high concentrations of iron impacted the nitrate concentration measurement. The mechanism for this effect has not been determined; however, after diluting the sample solution 1:10 results agreed with calculated values. By using a dilution on the process solutions we are able to minimize 
the corrosion of stainless steel analyzer components and aid in cooling the solution. Dilution over a range of 1:10 to 1:50 were made and provide sufficient analyzer accuracy and precision. In practice, the minimum dilution and pathlength are used to minimize water which will be returned to the process. Path length is limited by the maximum acceptable back pressure created by the flow cell as the lenses are moved closer toghether. There is additional need to study the effect of metal nitrates formed during this process.

To confirm our capability to make accurate measurements using the UV absorption technique, two electrochemical analysis techniques were developed on an Orion Autotitrator. The first was an acid titration where nitric acid concentration is calculated as the difference between the first and second endpoints(First endpoint provides the sum of nitric plus phosphoric acid and the second endpoint corresponds to the phosphoric acid concentration). The second method used a nitrate ion selective electrode and measures nitrate based on a standard addition technique. These experiments comparing the three methods over the range of process solutions expected found excellent correlation between the electrochemical methods and UV absorption spectrophotometer. Sample prep for the titration and standard addition methods required gravimetric dilution to achieve sufficient precision and accuracy. Each sample require about 15 minutes per analysis suggesting that these techniques will remain valuable as a back-up for the spectrophotometer.

The current analyzer consists of a short pathlength $(0.025 \mathrm{~mm})$ stainless steel flow cell with fused silica optics, UV grade fiber-optic cables, a xenon flash lamp for high UV output and an HP8452 spectrophotometer. The HP8452 was selected based solely on current availability with 2 other smaller, higher sensitivity instruments under development(funded by Savannah River for other applications). The flash lamp provides an extended lifetime and greater light intensity for UV applications over the more common deuterium lamps used for UV analysis. This system was developed as a fiberoptic application based on the eventual need to make these measurements in a glovebox for processing alpha contaminated materials. After testing multiple pump and static mixer configurations, we have identified a set-up capable of delivering low sample volumes with sufficient precision to provide accurate at-line measurements without using gravimetric dilutions. The peristaltic pump selected has 4 channels and is adjustable at $1 \%$ intervals over it operating range. Three of the channels use 0.125 inch ID tubing for water and the fourth uses .0625 inch ID tubing for process sample. This pumping arrangement allows for approximately a 1:10 dilution of the process solution over a broad flow range.

The system is calibrated and calibration checks are performed by pulling sample from standard solutions instead of the process vessel. The calibration curve is made using a Principle Component Regression model consisting of 3 eigen vectors after a second derivative of the absorption spectrum has been calculated. This modeling technique has been demonstrated for nitrate concentrations over a range of 0.1 to $1.5 \mathrm{M}$. The spectrophotometer operating software automatically applies this model to sample measurements and provides a near real-time readout of the process nitrate concentration. 
Further software development will be required to allow this number to be used for feedback control; however, similar developments are being pursued for similar projects using different spectrophotometers. This software is also capable of using multiple models over various wavelength ranges so the visible absorptions of iron and plutonium can be measured simultaneously.

Monitoring of additional materials using a single spectrophotometer takes advantage of multiplexing technology and is an added benefit of using fiber-optic equipped spectrophotometers. To implement additional applications, we can anticipate that longer pathlength flow cells are needed, but these could be placed either in the digestion vessel or in the sample stream upstream of the dilution pump. UV absorption analyzers have been demonstrated by others to measure $\mathrm{NO}, \mathrm{NO} 2$, and $\mathrm{H} 2 \mathrm{O} 2$ for process control. With this in mind, we can anticipate using the nitrate monitoring instrument to monitor off-gas along with nitric acid build-up and peroxide depletion in the acid recovery unit.

\section{H. Metal Retention/Behavior of Plutonium and Uranium}

Discussion: When organic materials contaminated with radioactive metals are oxidized, the radioactive metals are given a certain "mobility" within the system. It is expected that the metals will dissolve into the mixed acid bath and remain there until it is time to immobilize the spent acid. It is important to retain the radioactive metals in the mixed acid in. order to prevent contamination from entering the acid recovery system and escaping the overall process through the offgas system. Extra benefits can be drawn if radioactivity in the acid recovery system can be kept sufficiently low so as to permit the placement of vessels outside of containment or in areas of increased operator access. Experiments were conducted using both nonradioactive simulants and actinides to assess their fractionation within the system.

Results:

Plutonium experiments were conducted to help gain an understanding into how much carryover of plutonium, if any, occurs during operation. A series of initial tests were conducted using paper, neoprene, and polyethylene at varying process conditions and system air flows. In our experiments, a phosphoric acid solution containing $1 \times 10^{6}$ $\mathrm{dpm} / \mathrm{mL}$ of $\mathrm{Pu}-239$ was made and used to contaminate samples and as the oxidation vessel liquid. The system has a 1.5 liter oxidation vessel containing $600 \mathrm{~mL}$ of phosphoric acid. Nitric acid is pumped into the system as needed. Gases leaving the system flow through a column of glass beads (which functions as a mist eliminator) before passing through a series of three wash bottles representing the acid recovery system. Analytical data for a series 10 tests with small quantities of paper, neoprene and polyethylene showed that the alpha activity in the three wash bottles for all three test conditions was below $6.5 \mathrm{E}+01 \mathrm{dpm} / \mathrm{mL}$ for all samples.

Next, a set of experiments was conducted with increasing amounts of cellulose added as a batch ranging from one gram to five grams to examine what happens during high reaction 
rates and large volumes of gas generation.. In each of these tests, although gas generation rates were extremely high, alpha activity in the wash bottles was below the detection limit of $6.5 \mathrm{E}+01$.

One longer test processed 25 grams of cellulose through $600 \mathrm{~mL}$ of solution over the course of one hour. Consistent with previous results, no carryover of plutonium was detected in the wash bottles. A total organic carbon analysis of the first wash bottle from this run showed only $395 \mathrm{ppm}$ of organic carbon in $100 \mathrm{~mL}$ of hydrogen peroxide. A rinse of the mist eliminator using $20 \mathrm{~mL}$ of dilute acid showed $6.7 \mathrm{E}+02 \mathrm{dpm} / \mathrm{mL}$ of alpha activity had accumulated for the entire set of 17 experiments.

A final test was run with six cellulose filters, each weighing about 3 grams, containing a total of 2.5 grams of uranium oxide powder between them. Consistent with the plutonium data, uranium was below $0.01 \mathrm{ppm}$ in the wash bottles. A $10 \mathrm{~mL}$ rinse of the mist eliminator detected $0.088 \mathrm{ppm}$ of uranium. The final uranium content of the phosphoric acid was 3600 ppm.

Parallel experiments were conducted in the pilot-scale unit using zinc as a stand-in for plutonium. This was done because zinc is a metal not expected to be found in stainless steel, and offgas cooling coils were made from stainless steel; also, zinc would be easy to measure without submitting for analysis by ICP. Early experiments conducted during cellulose oxidation showed little or no zinc coming out of the system in the chloride wash bottle. However, when chloride-containing compounds were destroyed in the system, zinc carryover went up more than an order of magnitude. We are looking into zinc chloride volatility as an explanation for this behavior in comparison to the different behavior displayed during plutonium testing. Consequently, future experiments will look to using cerium as a stand-in for plutonium.

\section{Final Waste Forms}

Discussion: The value of any organic waste treatment process is strongly dependent upon the ability to safely and conveniently place any hazardous or radioactive metals in a stable final waste form. The use of a phosphoric acid matrix provides at least two final waste forms, iron phosphate $(\mathrm{FeP})$ glass and magnesium phosphate $(\mathrm{MgP})$ ceramic. The ceramic is made at ambient temperatures and is stable enough to pass the new.Universal Treatment Standards (UTS) for hazardous metals. This makes it valuable for immobilizing RCRA metals and short-lived radioisotopes such as $\mathrm{Cs}-137$ and $\mathrm{Sr}-90$. The iron phosphate glass melts at $1050-1150^{\circ} \mathrm{C}$ and has the stability of a high-level waste glass, thereby making it valuable for immobilizing actinide metals. In comparison, the ceramic is more convenient to make while the glass provides a greater volume reduction and more stable form.

Results: SRTC hosted Dileep Singh of Argonne National Laboratory to discuss the use of magnesium phosphate ceramics for making an immobilized waste form. Magnesium phosphate is the preferred waste form of the Mixed.Waste Focus Area. We worked in the 
lab making samples from spent phosphoric acid waste streams and learned how to make the samples. As a follow-up to the visit of Dileep Singh of Argonne National Laboratory, samples of magnesium phosphate ceramic were made with a phosphoric acid stream used to destroy organics contaminated with both plutonium and uranium.

Two different compositions were made and no problems were experienced as the acid was effectively and easily immobilized. The first sample used 30 grams of $90 \% \mathrm{H}_{3} \mathrm{PO}_{4}$, $29.7 \mathrm{~g} \mathrm{H} 2 \mathrm{O}, 19.5 \mathrm{~g} \mathrm{KOH}, 13.8 \mathrm{~g} \mathrm{MgO}$, and $10.6 \mathrm{~g}$ of $\mathrm{KH}_{2} \mathrm{PO}_{4}$. We started with the $\mathrm{H}_{3} \mathrm{PO}_{4}$ and then gradually added a mixture of the $\mathrm{KOH}$ and water over a 20-25 minute period. Next, a mixture of the $\mathrm{MgO}$ and $\mathrm{KH}_{2} \mathrm{PO}_{4}$ were added all at once. The solution was stirred for seven minutes and then poured into a mold. The solution was stirred in the mold for an extra two minutes before being allowed to cure over the next 30-45 minutes. The sample was cured for two weeks before being submitted for leach testing.

In the second sample, the water content was reduced by 4.2 grams. Once again, we started with the $\mathrm{H}_{3} \mathrm{PO}_{4}$ and then gradually added a mixture of the $\mathrm{KOH}$ and water over a 20-25 minute period. Then a mixture of the $\mathrm{MgO}$ and $\mathrm{KH}_{2} \mathrm{PO}_{4}$ were added all at once. Due to the reduced water content, the second sample got much hotter and began to set up quicker. The sample was stirred for one minute (as compared to seven minutes in sample 1) before being poured in the mold. The sample was stirred an additional three to four minutes before it began solidify to an extent that stirring need to stop. The sample was allowed to cure for two weeks before submitting for leach testing.

The samples were leach tested using a modified TCLP method. The results show that Si, $\mathrm{PO}_{4}{ }^{3-}$ and $\mathrm{NO}_{3}{ }^{-}$leach from the second sample at 2-3 times the rates observed in the first sample. Furthermore, the first sample showed less that $0.007 \mathrm{mg} / \mathrm{L} \mathrm{Mg}$ leached versus $309 \mathrm{mg} / \mathrm{L} \mathrm{Mg}$ for the second sample. Discussions with Dileep Singh indicated that the differences is linked with the rapid solidification of the second sample in that it did not have sufficient time to cure properly. Due to problems in the analysis, samples had to be re-submitted for analysis of potassium and uranium.

One major concern with the ceramic, especially for $\mathrm{Pu}-238$ waste, is radiolysis of water to form hydrogen gas. It has been shown that certain cement waste forms with bound and unbound water in the matrix will radiolyze readily to form hydrogen gas. However, reports as early 1978 show that dried cementatious waste forms, heated to where the unbound water is driven off, have radiolytic hydrogen generation rates that are 2-3 orders of magnitude lower. This has been confirmed in later work.

Follow-up studies were conducted on a potassium magnesium phosphate ceramic (KMgP). We performed thermogravimetric analysis (TGA) which monitors weight loss as a function of temperature. Samples were also heated to 200,400 , and 600 degrees $C$ and analyzed using $\mathrm{X}$-ray diffraction (XRD). TGA shows that $\mathrm{KMgP}$ readily loses water from $100-250^{\circ} \mathrm{C}$ and then has little or no more detectable weight loss. This is confirmed by $\mathrm{XRD}$ which shows $\mathrm{KMgPO}_{4}-6 \mathrm{H}_{2} \mathrm{O}$ at room temperature, a mixture of transition products at $200^{\circ} \mathrm{C}_{2}$ and anhydrous $\mathrm{KMgPO}_{4}$ at $400^{\circ} \mathrm{C}$ and $600^{\circ} \mathrm{C}$. This suggests that a 
final waste form made from $\mathrm{KMgP}$ could be heated up to make an anhydrous form which has acceptably low radiolytic hydrogen generation. Additional testing needs to be conducted in FY98 to prove that an acceptable waste form can be produced using $\mathrm{KMgP}$.

Nonradioactive work was conducted on iron phosphate glass to identify a glass composition to be used in immobilizing radioactive solutions. Testing examined the range which can be used for processing the spent phosphoric acid solutions. The range for $\mathrm{Fe}_{2} \mathrm{O}_{3}$ is $15-45 \mathrm{wt} \%, \mathrm{Na}_{2} \mathrm{O}$ is $0-6$ wt.\%, and $\mathrm{SrO}$ is $0-3$ wt.\%. Glasses were consistently formed from glasses containing $20-40 \% \mathrm{Fe}_{2} \mathrm{O}_{3}$ and small amounts of $\mathrm{Na}_{2} \mathrm{O}$ and $\mathrm{SrO}$. Based on the quality of glasses formed, the target glass will use $33 \% \mathrm{Fe}_{2} \mathrm{O}_{3}$, $5.5 \% \mathrm{Na}_{2} \mathrm{O}, 2.5 \% \mathrm{SrO}$, and $59 \% \mathrm{P}_{2} \mathrm{O}_{5}$. This composition will allow significant fluctuation in the composition without jeopardizing glass formation.

As a follow-up, glasses were made using a corrosion test solution containing large levels of hazardous and other dissolved metals $(\mathrm{Al}=234 \mathrm{ppm}, \mathrm{Co}=214 \mathrm{ppm}, \mathrm{Cr}=4068 \mathrm{ppm}$, $\mathrm{Ni}=10584 \mathrm{ppm}$ ). The target concentration of the glass was $33 \% \mathrm{Fe}_{2} \mathrm{O}_{3}, 59 \% \mathrm{P}_{2} \mathrm{O}_{5}, 5.5 \%$ $\mathrm{Na}_{2} \mathrm{O}$, and $2.5 \% \mathrm{SrO}$. Samples were submitted for leach testing using the Product Consistency Test (PCT). . Leach tests showed no measureable leaching of hazardous metals; also, a comparison of sodium leaching indicates that the iron phosphate glass is at least as resistant to leaching as the borosilicate glass standards. This is consistent with the expected results.

Final experiments were conducted in making three glass samples using the solution from plutonium and uranium testing. Three samples were made using 20,30, and $40 \% \mathrm{Fe}_{2} \mathrm{O}_{3}$ along with 2.0, 2.5, and $3.0 \% \mathrm{SrO}$, and 4,5 , and $6 \% \mathrm{Na}_{2} \mathrm{O}$, respectively. Glasses were formed from the solutions containing 30 and $40 \% \mathrm{Fe}_{2} \mathrm{O}_{3}$. These were awaiting leach testing at the end of the year.

\section{J. Waste Feed Mechanisms/Material Transport}

Discussion: The ability to chemically treat a waste is important, but its success can be overshadowed if there is an inability to feed the process and draw materials from the process in a simple, safe, and reliable manner. Tests were conducted on the bench and engineering-scale units to assess the effectiveness of three different waste feed options. The options include 1) a feed screw, 2) semi-batch injection, and 3) oxidation in a bypass loop. Also, evaluations were made regarding the transport characteristics of other liquid and gas streams within the process.

Results: Testing of the three feed mechanisms followed expectations. The use of a feed screw was used on the bench scale and found to be effective in delivering controlled quantities of material to the oxidation pot. The primary concern with this approach revolves around the need to prevent acid vapors from work their way into the feed system. The was particularly problematic when feeding a resin waste stream in that it made the waste more difficult to transport. This was partially overcome by supplying a small air stream through the feeder into the reaction vessel. 
Use of semi-batch injection worked well, but was found to be a cumbersome process. Experience showed semi-batch injection to be labor intensive and it introduced larger variations in reaction conditions due to higher instantaneous waste loading. Also, because large charges are injected, the efficiency of reaction using this type of feeder is less than a screw feeder. This approach also raises concerns regarding acid in the feeder which may cause the feeding mechanism to become plugged.

The application of a bypass loop was tested at the bench scale and shown to provide some promise. The principles behind the approach worked well and generation of offgas did not seem to be a problem. Additionally, the approach provides good liquid-solid contact without the use of stirring in the reaction vessel. Furthermore, the use of a bypass loop offers an additional benefit in that any materials which do not dissolve quickly are not fed directly to the oxidation vessel where they form a heel in the bottom of the tank. This approach may also be used to conduct a partial oxidation of the waste and a decontamination of the remaining materials. Concerns exist in that cooling of the oxidation liquid occurs between the reaction vessel and the waste holder, materials of construction may be an issue, and the charging of waste will be more complicated than a screw feeder. Based on the pros and cons, it is believed that this is the most appropriate option for this waste stream and ought to be studied at greater length.

There is potential that customer requirements for $\mathrm{Pu}-238$ job control waste will push the development toward the least amount of handling practicable, even at the expense of process throughput. Job control waste from $\mathrm{Pu}-238$ operations is historically bagged four to six times. As a result, it is expected that each package of waste will be essentially clean on the outside, and easy to charge to a reaction vessel as a single unit. Because of this and concerns over contamination control, it is undesirable that the bags be opened prior to being charged to the oxidation vessel. Methods for performing this operation in a way which is compatible with downstream operations are being evaluated in conjunction with the customer.

Transport of other liquids and gases was observed in the system. No problems or concerns were observed with respect to either gases or liquids. Transport of the spent phosphoric acid in both lab and pilot testing was easily performed using standard peristaltic pumps. The success of gas and liquid transport was consistent with what was expected.

\section{K. System Operability and Reliability}

Discussion: As a companion to the previous discussion on waste feed and material transport, serious consideration must also be given to the overall operability and reliability of the system. This becomes increasingly important as one considers the prospect of placing a wet chemical oxidation system in a glovebox or remote environment where it must be operated and maintained. Emphasis must be placed on 
ease and number of hands-on operations, consistency of operations, and reliability of both design and equipment.

Results: The overall operation of the system was consistent with the expected design. Heating of the reaction vessel was quick, reliable, and controllable with the heating mantle and temperature controllers selected. Gas seals were generally reliable throughout the system and leaks were isolated incidents. We did experience some difficulty in creating a seal at elevated pressures around the 12" flange of the oxidation vessel. However, due to the size of the sealing area, it was expected that there might be some problems in obtaining a good seal. Stirring, which was an area of concern, was effective and reliable; however, the demands placed on stirring were not very high. The oxidation vessel mist eliminator had to be modified from its original design. The original approach simply employed a packed-bed using burl saddles. It was observed that nitric acid evaporation was excessive so the mist eliminator was modified to include a cooling coil. This greatly reduced the nitric acid losses due to evaporation. However, controlling of nitric acid evaporation still remains a primary process concern.

Process monitoring also proved to be reliable and responsive. Temperature and pressure readings were made on a real-time basis and recorded in the data acquisition system. Consistency of data was confirmed in places where multiple temperature and pressure readings were taken. The response of the pressure transducers under the process conditions used was noteworthy. Problems were observed in the use of the rotameters due to the collection of moisture in them. It is recommended that an alternative technology be employed for the next system.

Another process area which functioned mechanically as designed was the NOx scrubbing system for acid recycle. The sequential gas dispersion vessels were effective in removing $\mathrm{NOx}$ and $\mathrm{HCl}$ vapors from the offgas stream. Throughout runs in which our offgas monitor was working, NOx levels were maintained below the $200 \mathrm{ppm}$ limit mandated by the Clean Air Standards. As discussed in Section C on chloride removal, some flaws exist in the proposed theory for chloride and NOx removal. Some problems occurred in the acid recovery system due to materials selection. It was observed that mixtures of hydrogen peroxide and nitric acid caused some etching of the glass vessel and generated silica precipitates which tended to plug the gas bubblers. This is not expected to occur if alternate materials are used.

The most noteworthy operability issue addressed was that of pressure control. Although the system was equipped with pressure control valves, it was demonstrated that the proper design of the offgas bubblers was sufficient to create the necessary oxidation vessel backpressure without restricting flow through the use of valves. What this means is that no valves need to be turned during steady-state operation of the oxidation vessel and offgas system; this is of great importance when considering glovebox operations.

Another area for optimism revolves operability and maintenance of acid scrubbing and recycle equipment_ Results from tests on the mist eliminator indicate a containment of 
radioactive material within the oxidation vessel and the mist eliminator; no radioactivity has been detected downstream of the mist eliminator. If this trend can be maintained in future pilot-scale activities, it is conceivable that acid scrubbing and recycle equipment could be constructed and operated in an area with reduced shielding and containment requirements. As a result, the only operations which would require high-level shielding and containment would be feeding, oxidation, and acid immobilization. This would greatly improve the overall simplicity of operating and maintaining the process.

Two other areas where improvements need to be made are waste feeding and sampling. The need for improved waste feeding has been addressed in Section J. Sampling was quite burdensome because it was decided to conduct manual analysis of quantities such as acid concentration and chloride levels. Approaches are being evaluated for the on-line measurement of these quantities. Some of this is addressed in Section G.

\section{FY97 CONCLUSIONS}

Experimental work in FY97 advanced the technology towards demonstrating viability as a production-scale system. Key issues such as NOx recycle, materials of construction, dioxin formation, process monitoring, acid immobilization, radionuclide entrainment, and operability were successfully addressed. Concerns regarding waste throughput were also addressed on a small scale, but were limited due to waste feeding problems at the 40 -liter scale. Increases can be realized through elevated temperatures and pressures well within the TDRD limits, but are not desired by SRS Solid Waste Management. Open issues still exist with regards to chloride stripping, nitric acid volatility, waste form radiolysis, and waste feeding - solutions have been proposed, but have not yet been evaluated. It is recommended that work for FY98 should focus on resolving these open issues and completing the design of a pilot-scale unit for testing in FY99. 